\title{
Optimization on Preparation Condition of Propolis Flavonoids Liposome by Response Surface Methodology and Research of Its Immunoenhancement Activity
}

\author{
Ju Yuan, ${ }^{1}$ Yu Lu, ${ }^{2}$ Saifuding Abula, ${ }^{3}$ Yuanliang Hu, ${ }^{1}$ Jiaguo Liu, ${ }^{1}$ Yunpeng Fan, \\ Xiaojuan Zhao, ${ }^{1}$ Deyun Wang, ${ }^{1} \mathrm{Xu} \mathrm{Liu,}{ }^{1}$ and Cui Liu ${ }^{1}$ \\ ${ }^{1}$ Institute of Traditional Chinese Veterinary Medicine, College of Veterinary Medicine, Nanjing Agricultural University, \\ Nanjing 210095, China \\ ${ }^{2}$ National Research Center of Veterinary Biologicals Engineering and Technology, Jiangsu Academy of Agricultural Science, \\ Nanjing 210014, China \\ ${ }^{3}$ College of Veterinary Medicine, Xinjiang Agricultural University, Urumchi 830052, China
}

Correspondence should be addressed to Deyun Wang; dywang@njau.edu.cn

Received 23 October 2012; Revised 26 January 2013; Accepted 31 January 2013

Academic Editor: Zenon Czuba

Copyright (C) 2013 Ju Yuan et al. This is an open access article distributed under the Creative Commons Attribution License, which permits unrestricted use, distribution, and reproduction in any medium, provided the original work is properly cited.

\begin{abstract}
The aim of this study is to prepare propolis flavonoids liposome (PFL) and optimize the preparation condition and to investigate further whether liposome could promote the immunoenhancement activity of propolis flavonoids (PF). PFL was prepared with ethanol injection method, and the preparation conditions of PFL were optimized with response surface methodology (RSM). Moreover, the immunoenhancement activity of PFL and PF in vitro was determined. The result showed that the optimal preparation conditions for PFL by response surface methodology were as follows: ratio of lipid to drug (w/w) $9.6: 1$, ratio of soybean phospholipid to cholesterol (w/w) $8.5: 1$, and speed of injection $0.8 \mathrm{~mL} \cdot \mathrm{min}^{-1}$. Under these conditions, the experimental encapsulation efficiency of PFL was $91.67 \pm 0.21 \%$, which was close to the predicted value. Therefore, the optimized preparation condition is very reliable. Moreover, the results indicated that PFL could not only significantly promote lymphocytes proliferation singly or synergistically with PHA, but also increase expression level of IL- 2 and IFN- $\gamma$ mRNA. These indicated that liposome could significantly improve the immunoenhancement activity of PF. PFL demonstrates the significant immunoenhancement activity, which provides the theoretical basis for the further experiment in vivo.
\end{abstract}

\section{Introduction}

Natural products are a promising source for the discovery of new pharmaceuticals. In the last decades, several works dealing with propolis composition and biological properties have been published, revealing the interest of researchers on this bee product and its potential for the development of new drugs as well [1-4]. Propolis has been employed extensively since ancient times in Egypt, Greece, Roman Empire, and so on. Its use continues today as a popular remedy and is available in either in pure form or combined with other natural products in cosmetics and as a constituent of healthy foods.
Propolis presents plenty of biological and pharmacological properties, such as immunomodulatory, antitumor, antiinflammatory, antioxidant, antibacterial, antiviral, antifungal, and antiparasite activities, among others [5-10]. Propolis mechanisms of action have been widely investigated in the last years, using different experimental models in vitro and in vivo. Researchers have been interested in the investigation of isolated compounds responsible for propolis action and find flavonoids are one of the most important groups [11]. Propolis flavonoids (PF) are responsible for many of its biological and pharmacological activities [12]. Although PFs have good effect as antioxidant, antitumor, immunomodulatory, and so forth, they are easy to be oxidized [13], which makes the 
flavonoids themselves be not stable. The storage, use, and function of propolis were affected with its instability.

Liposome is a synthetic bilayer membrane vesicle with phosphorus and has good affinity on cell membrane. For their biodegradability, biocompatibility, low toxicity, and their ability to entrap both lipophilic and hydrophilic drugs [14], liposomes are known for their potential and actual uses in targeted drug delivery. If PFs are encapsulated with liposome, their stability will be increasingly promoted. However, the effective factors on preparation of propolis flavonoids liposome (PFL) are various, and the preparation conditions need to be optimized. In additional, it is also important whether the biological activity is changed with liposome encapsulation.

Response surface methodology (RSM) is a collection of mathematical and statistical techniques useful for analyzing the effects of several independent variables [15-17]. In many processes, the relationship between the response and the independent variables is usually unknown; therefore the first step in RSM is to approximate the function (response) in terms of analyzing variables (independent variables). Usually, this process employs a low-order polynomial equation in a predetermined region of the independent variables, which is later analyzed to locate the optimum values of independent variables for the best response [17].

Therefore, in the present study, RSM was employed to optimize the preparation conditions of PF, and the biological activity of PF was compared between preencapsulation and postencapsulation. The aim of this strategy is to optimize the best preparation condition of PFL and observe immunoenhancement activity in vitro, which provide the theoretical basis for the further experiment in vivo to study whether PFL could promote immune response.

\section{Materials and Methods}

2.1. Materials. Propolis was purchased from Dahua Chinese Traditional Medicine Company in Nanjing, Jiangsu Province. PFs were prepared in our laboratory (briefly, propolis was extracted with $95 \%$ ethanol for three times, and the ethanol solution was retrieved. Then, the precipitation was extracted with ethyl acetate for three times, and then the ethyl acetate was retrieved. Finally, the precipitation was dried in vacuum, and PF was obtained.). Soybean phospholipid (number 20110908) was manufactured by Shanghai Taiwei Pharmaceutical Co., Ltd, and Cholesterol (number 20110706) purchased from Anhui Tianqi Chemical Technology Co., Ltd. Protamine (Sigma, P4380) was dissolved by physiological saline to $10 \mathrm{mg} \mathrm{mL}^{-1}$. Lymphocyte separation medium (number 110326) was manufactured by Shanghai Huajing Biology Inc. RPMI-1640 (GIBCO) with the supplement of $100 \mathrm{IU} \mathrm{mL}^{-1}$ benzylpenicillin, $100 \mathrm{IU} \mathrm{mL}^{-1}$ streptomycin, and $10 \%$ fetal bovine serum was used for washing and resuspending cells, diluting mitogen, and culturing the cells. Phytohemagglutinin (PHA, Sigma, number L-8754), as a Tcell mitogen, was dissolved into $0.1 \mathrm{mg} \mathrm{mL}^{-1}$ with RPMI1640. Hanks' solution was used for diluting blood. The 3(4,5-dimethylthiazol-2-yl)-2,5-diphenyltetrazolium bromide
(MTT, American Co.) was dissolved into $5 \mathrm{mg} \mathrm{mL}^{-1}$ with calcium and magnesium-free (CMF) phosphate-buffered saline (PBS, pH 7.2). These reagents were filtered through a 0.22 $\mu \mathrm{m}$ millipore membrane filter. PHA solution was stored at $-20^{\circ} \mathrm{C}$, MTT solution at $4^{\circ} \mathrm{C}$ in dark bottles, and RPMI-1640 at $4^{\circ} \mathrm{C}$. Dimethyl sulfoxide (DMSO, number 20090519) was produced by Kemou Institute of Chemical Engineering in Tianjing, 5x PrimeScript RT Master Mix, SYBR Premix Ex Taq, ROX Reference Dye (50x), Takara Inc.

2.2. Preparation of PF Liposome. Propolis flavonoids (PF) liposome was prepared with ethanol injection method [18]. Lecithin, cholesterol, and propolis flavonoids were dissolved in about $10 \mathrm{~mL}$ of ethanol, and the ethanol was injected into the buffer $\left(40^{\circ} \mathrm{C}, \mathrm{PBS}\right)$ with a slow speed and continued to thermostatic mixing. Liposomes formed spontaneously after further evaporation of the residual ethanol. The resulting mixture was homogenized with ultrasonication for $30 \mathrm{~min}$ to form the small single-chamber liposome (Ultrasonic Cleaner KQ5200B, Kunshan Sonicatic equipment Inc. China) [18]. Ultimately, the solution was filtered with $0.8 \mu \mathrm{m}, 0.45 \mu \mathrm{m}$, and $0.22 \mu \mathrm{m}$ millipore membrane successively [19].

\subsubsection{Entrapment Efficiency (EE) of PFL Array. $0.8 \mathrm{~mL}$ of} PFL was added in $10 \mathrm{~mL}$ centrifuge tube and mixed with $0.8 \mathrm{~mL}$ of protamine solution $\left(10 \mathrm{mg} \cdot \mathrm{mL}^{-1}\right)$. After $3 \mathrm{~min}$, $3.0 \mathrm{~mL}$ of physiological saline was added. After adequate mixing, this suspension was centrifuged at $3000 \times \mathrm{r} \cdot \mathrm{min}^{-1}$ at the room temperature for $30 \mathrm{~min}$. All supernatant was taken from centrifuge tube, setting the volume to $10 \mathrm{~mL}$ with physiological saline, $5 \mathrm{~mL}$ was taken to assay the content of PF by ultraviolet spectrophotometry method with Rutin standard substance [20], and the content of PF was called the content of free drug. The precipitation remaining in centrifuge tube was dissolved by $3.0 \mathrm{~mL}$ of Triton X-100 and then setting the volume to $10 \mathrm{~mL}$ with physiological saline. Five millilitres of the solution were taken to assay the content of PF by Rutin standard method and called the content of encapsulated drug. The formula to calculate liposome encapsulation efficiency was $\mathrm{EE} \%=\left(1-C_{f} / C_{t}\right), C_{f}$ : the content of free drug, $C_{t}$ : the total content of drug [21-23].

2.2.2. Optimization of PFL Preparation. Based on the singlefactor test, three factors, ratio of lipid to drug w/w (A), ratio of soybean phospholipid to cholesterol w/w (B), and speed of injection $/ \mathrm{mL} \cdot \mathrm{min}^{-1}(\mathrm{C})$, were selected to optimize the preparation conditions of PF liposome. The selected factors were subjected to response surface methodology (RSM) with a three-factor three-coded level Box-Behnken design (BBD) to optimize the preparation conditions of PFL. The range and the levels of experimental variables investigated in this study are presented in Table 1 . In addition, several verification experiments were done according to the optimal conditions.

\subsection{Immunoenhancement Activity of PFL In Vitro}

2.3.1. T Lymphocyte Proliferation Assay. Blood samples were collected from nonimmunized White Roman chickens at 60 
TABLE 1: Factors and levels of Box-Behnnken experimental design.

\begin{tabular}{lcccc}
\hline \multirow{2}{*}{ Factors } & Code & \multicolumn{4}{c}{ Range and levels } \\
& & -1 & 0 & 1 \\
\hline A ( ratio of lipid to drug, w/w) & $X_{1}$ & $5: 1$ & $10: 1$ & $15: 1$ \\
$\begin{array}{l}\text { B (ratio of soybean phospholipid } \\
\text { to cholesterol, w/w) }\end{array}$ & $X_{2}$ & $6: 1$ & $8: 1$ & $10: 1$ \\
C (speed of injection, $\mathrm{mL} \cdot \mathrm{min}^{-1}$ ) & $X_{3}$ & 0.3 & 0.6 & 1.2 \\
\hline
\end{tabular}

days old (provided by Tangquan Poultry Farm), transferred immediately into aseptic capped tubes containing sodium heparin, then diluted with an equal volume of Hanks' solution, and carefully layered on the surface of lymphocyte separation medium. After centrifugation at $800 \times \mathrm{g}$ for $15 \mathrm{~min}$, the lymphocytes were collected and washed twice with Hanks' solution. The resulting pellet was resuspended and diluted to $2.5 \times 10^{6} \mathrm{~mL}^{-1}$ with RPMI-1640 with fetal bovine serum after the cell viability was assessed by trypan blue exclusion. The solution was divided into two parts: one part was added with PHA, and the other part was directly added. They were, respectively, incubated into 96-well culture plates, $100 \mu \mathrm{L}$ per well. Then, PFL, PF, and BL at series of concentrations were added, in cell control group and PHA control group, RPMI-1640 medium and PHA, respectively, $100 \mu \mathrm{L}$ per well, four wells each concentration. The final concentration of PHA reached to $20 \mu \mathrm{g} \mathrm{mL}^{-1}$. The plates were, respectively, incubated in a humid atmosphere with $5 \% \mathrm{CO}_{2}$ (Revco, Co., USA) at $39.5^{\circ} \mathrm{C}$ for $48 \mathrm{~h}$. Briefly, $30 \mu \mathrm{L}$ of MTT $\left(5 \mathrm{mg} \mathrm{mL}^{-1}\right)$ was added into each well at $4 \mathrm{~h}$ before the end of incubation. Then the plates were centrifuged at $1000 \times \mathrm{g}$ for $10 \mathrm{~min}$ at room temperature. The supernatant was removed carefully, and $100 \mu \mathrm{L}$ of DMSO was added into each well. The plates were shaken for $5 \mathrm{~min}$ to dissolve the crystals completely. The absorbance of cells in each well was measured by microliter enzyme-linked immunosorbent assay reader (Model RT6000, Leidu Co., Ltd. Shenzhen City) at a wavelength of $570 \mathrm{~nm}\left(A_{570}\right.$ value $)$ as the index of lymphocytes proliferation [24].

\subsubsection{The Experiment of Gene Expression}

Preparation of Lymphocyte. Blood samples were collected from nonimmunized White Roman chickens at 60 days old (provided by Tangquan Poultry Farm), transferred immediately into aseptic capped tubes containing sodium heparin, then diluted with an equal volume of Hanks' solution, and carefully layered on the surface of lymphocyte separation medium. After centrifugation at $800 \times \mathrm{g}$ for $15 \mathrm{~min}$, the lymphocytes were collected and washed twice with Hanks' solution. Cell viability was assessed by trypan blue exclusion. The resulting pellet was resuspended and diluted to $1.0 \times 10^{7} \mathrm{~mL}^{-1}$ with RPMI-1640 with fetal bovine serum and incubated in 24-well culture plates with $0.8 \mathrm{~mL} /$ well, then different concentrations PFL and PF were added into, and each sample seeded four wells, $1.0 \mathrm{~mL}$ per well. PHA with a working concentration $20 \mu \mathrm{g} / \mathrm{mL}$ was used for the purification of lymphocytes. The final volume of each well reached to $2.0 \mathrm{~mL}$. The lymphocytes were collected to isolate the RNA to amplify IL-2 and IFN- $\gamma$ after the plates were incubated at $5 \% \mathrm{CO}_{2}$ at $39.5^{\circ} \mathrm{C}$ for $36 \mathrm{~h}$.

Total RNA Isolation. Total RNA was isolated from peripheral T lymphocyte by using Trizol Reagent (Invitrogen) following the illustration provided by the manufacturer. The quality of isolated RNA was determined by ultraviolet spectrophotometry, and the optical density was 1.8-2.0.

Reverse Transcription (RT). RT was performed according to literature [25]. Briefly, the system of reverse transcription was $10 \mu \mathrm{L}$, containing $400 \mathrm{ng}$ of total RNA, $2 \mu \mathrm{L} 5 \times$ PrimeScript RT Master Mix* (for real time), and adding RNase Free $\mathrm{dH}_{2} \mathrm{O}$ until $10 \mu \mathrm{L}$ at $37^{\circ} \mathrm{C}$ for $15 \mathrm{~min}, 85^{\circ} \mathrm{C}$ for 5 second, and $4^{\circ} \mathrm{C}$ for random period of time. First strand cDNAs were store at $-20^{\circ} \mathrm{C}$ until further use.

PCR Amplification. Amplification was carried out in a total volume of $20 \mu \mathrm{L}$. Each PCR reaction included $6.8 \mu \mathrm{L}$ of $\mathrm{dH}_{2} \mathrm{O}, 10.0 \mu \mathrm{L}$ of SYBR Premix Ex Taq $(2 \times), 0.4 \mu \mathrm{L}$ of PCR Forward Primer, $0.4 \mu \mathrm{L}$ of PCR Reverse Primer, $0.4 \mu \mathrm{L}$ of ROX Reference Dye (50x), and $2 \mu \mathrm{L}$ of cDNA. PCR cycling conditions included a $95^{\circ} \mathrm{C}$ heating step for $30 \mathrm{~s}$ at the beginning of every run. The tubes were then cycled at $95^{\circ} \mathrm{C}$ for $5 \mathrm{~s}$, annealed at $60^{\circ} \mathrm{C}$ for $31 \mathrm{~s}$, and extend at $72^{\circ} \mathrm{C}$ for $1 \mathrm{~min}$, 40 cycles. A melting curve was generated at the end of every run to ensure product uniformity [26]. The specific primer sequences used were as follows:

$$
\begin{aligned}
& \text { IL-2 (162 bp): } \\
& \text { 5'-CTTTGGCTGTATTTCGG-3', } \\
& \text { 5'-CTGGGTCTCAGTTGGTG-3'; } \\
& \text { IFN- } \gamma \text { (171 bp): } \\
& \text { 5'-GCTGACGGTGGACCTATT-3', } \\
& 5^{\prime} \text {-TCCTCTGAGACTGGCTCCTT-3'; }
\end{aligned}
$$

$$
\begin{aligned}
& \beta \text {-action (280 bp): } \\
& \text { 5'-ACGTCGCACTGGATTTCG-3 }{ }^{\prime}, \\
& 5^{\prime} \text {-TGTCAGCAATGCCAGGGT- }{ }^{\prime} .
\end{aligned}
$$

Analysis of relative gene expression data is referring to the literature [27].

2.4. Statistical Analysis. Data of optimization of PFL preparation are analyzed by Design-Expert 7.0 software (Stat-Ease, Inc), second-order polynomial equation, and ANOVA of the quadratic regression model, and the optimal conditions were showed. Data of immunoenhancement activity experiment are expressed as mean \pm standard errors (S.E.). Duncan, LSD's multiple range tests and $t$-tests were used to determine the 
TABLE 2: Response surface Box-Behnken design and experimental encapsulation efficiency (\%).

\begin{tabular}{|c|c|c|c|c|c|}
\hline \multirow{2}{*}{ Number } & \multicolumn{3}{|c|}{ Levels of independent factors } & \multicolumn{2}{|c|}{ Response EE (\%) } \\
\hline & $X_{1}$ & $X_{2}$ & $X_{3}$ & Practical acquired EE & Predicted acquired EE \\
\hline 1 & $5: 1$ & $8: 1$ & 0.3 & 76.00 & 74.99 \\
\hline 2 & $5: 1$ & $10: 1$ & 0.6 & 82.60 & 82.88 \\
\hline 3 & $15: 1$ & $6: 1$ & 0.6 & 76.90 & 76.62 \\
\hline 4 & $15: 1$ & $8: 1$ & 1.2 & 72.10 & 73.11 \\
\hline 5 & $10: 1$ & $10: 1$ & 1.2 & 82.04 & 81.41 \\
\hline 6 & $15: 1$ & $10: 1$ & 0.6 & 80.15 & 79.78 \\
\hline 7 & $10: 1$ & $6: 1$ & 0.3 & 76.40 & 77.03 \\
\hline 8 & $15: 1$ & $8: 1$ & 0.3 & 78.25 & 77.89 \\
\hline 9 & $10: 1$ & $6: 1$ & 1.2 & 77.00 & 76.27 \\
\hline 10 & $10: 1$ & $8: 1$ & 0.6 & 92.60 & 91.30 \\
\hline 11 & $10: 1$ & $8: 1$ & 0.6 & 90.78 & 91.30 \\
\hline 12 & $10: 1$ & $10: 1$ & 0.3 & 80.02 & 80.75 \\
\hline 13 & $10: 1$ & $8: 1$ & 0.6 & 91.00 & 91.30 \\
\hline 14 & $10: 1$ & $8: 1$ & 0.6 & 91.54 & 91.30 \\
\hline 15 & $5: 1$ & $6: 1$ & 0.6 & 76.80 & 77.17 \\
\hline 16 & $10: 1$ & $8: 1$ & 0.6 & 90.58 & 91.30 \\
\hline 17 & $5: 1$ & $8: 1$ & 1.2 & 79.30 & 79.66 \\
\hline
\end{tabular}

TABLE 3: Estimated regression model of relationship between response variables (EE) and independent variables $\left(X_{1}, X_{2}\right.$, and $\left.X_{3}\right)$.

\begin{tabular}{|c|c|c|c|c|c|}
\hline Source & Sun of squares & $\mathrm{df}$ & Mean square & $F$ value & $P$ value prob $>F$ \\
\hline Model & 700.32 & 9 & 77.81 & 75.33 & $<0.0001$ \\
\hline A & 6.66 & 1 & 6.66 & 6.45 & 0.0387 \\
\hline $\mathrm{B}$ & 39.21 & 1 & 39.21 & 37.96 & 0.0005 \\
\hline $\mathrm{C}$ & $6.612 \times 10^{-3}$ & 1 & $6.612 \times 10^{-3}$ & $6.402 \times 10^{-3}$ & 0.9385 \\
\hline $\mathrm{AB}$ & 1.63 & 1 & 1.63 & 1.57 & 0.2499 \\
\hline $\mathrm{AC}$ & 22.33 & 1 & 22.33 & 21.61 & 0.0023 \\
\hline $\mathrm{BC}$ & 0.50 & 1 & 0.50 & 0.49 & 0.5073 \\
\hline$A^{2}$ & 225.61 & 1 & 225.61 & 218.42 & $<0.0001$ \\
\hline$B^{2}$ & 99.76 & 1 & 99.76 & 96.58 & $<0.0001$ \\
\hline$C^{2}$ & 241.12 & 1 & 241.12 & 233.44 & $<0.0001$ \\
\hline Residual & 7.23 & 7 & 1.03 & & \\
\hline Lack of fit & 4.60 & 3 & 1.53 & 2.34 & 0.2150 \\
\hline Pure error & 2.63 & 4 & 0.66 & & \\
\hline Cor total & 707.55 & 16 & & & \\
\hline \multicolumn{3}{|c|}{$R^{2}=0.9898$} & \multicolumn{2}{|c|}{$R_{\mathrm{Adj}}^{2}=0.9766$} & \\
\hline
\end{tabular}

difference among groups. $P$ values of less than 0.05 were considered to be statistically significant.

\section{Results}

3.1. Statistical Analysis and the Model Fitting of PFL Preparation Optimization. There were 17 experimental runs for optimizing the three individual parameters in the BoxBehnken design (BBD), and the experimental conditions and the EE of PFL according to the factorial design were shown in Table 2. The results showed that the maximum EE value $(92.60 \%)$ was found in conditions of $X_{1}=10: 1, X_{2}$ $=8: 1$, and $X_{3}=0.6 \mathrm{~mL} \cdot \mathrm{min}^{-1}$. The values of regression coefficients were calculated, and the response variable and the test variables were related by the following second-order polynomial equation:

$$
\begin{aligned}
\mathrm{EE}= & 91.30-0.91 X_{1}+2.21 X_{2}-0.029 X_{3}-0.64 X_{1} X_{2} \\
& -2.36 X_{1} X_{3}+0.36 X_{2} X_{3}-7.32 X_{1}^{2}-4.87 X_{2}^{2}-7.57 X_{3}^{2} .
\end{aligned}
$$

The statistical significance of the regression model was checked by $F$-test and $P$ value, and the analysis of variance (ANOVA) for the response surface quadratic model was shown in Table 3. The determination coefficient $\left(R^{2}=\right.$ 0.9898), showed by ANOVA of the quadratic regression model, indicating that the model was highly significant and adequate for prediction within the range of experimental 
TABLE 4: Predicted and experimental values of the responses at optimum conditions.

\begin{tabular}{lcccc}
\hline & Ratio of lipid to drug $(\mathrm{w} / \mathrm{w})$ & $\begin{array}{c}\text { Ratio of soybean } \\
\text { phospholipid to cholesterol } \\
(\mathrm{w} / \mathrm{w})\end{array}$ & $\begin{array}{c}\text { Speed of } \\
\text { injection } /\left(\mathrm{mL} \cdot \mathrm{min}^{-1}\right)\end{array}$ & $\begin{array}{c}\mathrm{EE}(\%) \\
\text { Optimum conditions }\end{array}$ \\
Modified conditions & $9.630: 1$ & $8.470: 1$ & 0.760 & 0.8 \\
\hline
\end{tabular}

variables. The $P$ value was used as a tool to check the significance of each coefficient, and the smaller the $P$ value was, the more significant the corresponding coefficient was. In this table the linear coefficients $\left(X_{1}, X_{2}\right)$, a quadratic term coefficient $\left(X_{1}^{2}, X_{2}^{2}\right.$, and $\left.X_{3}^{2}\right)$, and the interaction coefficient $\left(X_{1} \times X_{3}\right)$ were found significantly $(P<0.05)$. The other term coefficients were not significant $(P>0.05)$. By the Design-Expert software to further optimize the preparation conditions, the optimum for preparation of PFL conditions obtained was as follows: ratio of lipid to drug (w/w) $9.6: 1$, ratio of soybean phospholipid to cholesterol (w/w) $8.5: 1$, and speed of injection $0.8 \mathrm{~mL} \cdot \mathrm{min}^{-1}$.

3.2. Verification of Predictive Mode. The suitable of the model equation for predicting the optimum response value was tested by using the selected optimal conditions. The maximum predicted and experimental value of EE was given in Table 4 . To ensure the predicted result was not biased toward the practical value, experiment rechecking was performed by these modified optimal conditions: ratio of lipid to drug (w/w) of $9.6: 1$, ratio of soybean phospholipid to cholesterol $(\mathrm{w} / \mathrm{w})$ of $8.5: 1$, and speed of injection $0.8 \mathrm{~mL} \cdot \mathrm{min}^{-1}$. A mean value of $91.67 \pm 0.21 \%(n=3)$ obtained from real experiments, demonstrated the validation of the RSM model, indicating that the model was adequate for the preparation process.

\subsection{Effect of PFL on T Lymphocyte Proliferation In Vitro}

\subsubsection{Effect of T Lymphocyte Proliferation in Single Stimulation} of Drugs. The results are listed in Figure 1. At $60-15 \mu \mathrm{g} \cdot \mathrm{mL}^{-1}$, the $A_{570}$ values of PFL group were the highest in those four groups and significantly higher than those of $\mathrm{PF}, \mathrm{BL}$, and cell control groups $(P<0.05)$. At $15-3.75 \mu \mathrm{g} \cdot \mathrm{mL}^{-1}$, the $A_{570}$ values of $\mathrm{PF}$ groups were significantly higher than those in $\mathrm{BL}$ and cell control group $(P<0.05)$.

\subsubsection{Effect of $T$ Lymphocyte Proliferation in Synergistical} Stimulation of Drugs with PHA. The results are shown in Figure 2. At $60-3.75 \mu \mathrm{g} \cdot \mathrm{mL}^{-1}$, the $A_{570}$ values of PFL group were the highest in those five groups. At $60-15 \mu \mathrm{g} \cdot \mathrm{mL}^{-1}$, the $A_{570}$ values of PFL group were significantly higher than those in PF, BL, PHA, and cell control groups $(P<0.05)$. At 7.5$3.75 \mu \mathrm{g} \cdot \mathrm{mL}^{-1}$, the $A_{570}$ values of PFL and PF groups were significantly higher than those in $\mathrm{BL}, \mathrm{PHA}$, and cell control groups $(P<0.05)$.

3.3.3. Effect of PFL on Expression Level of IL-2 $m R N A$. The results are listed in Figure 3. IL-2 mRNA level of PFL and

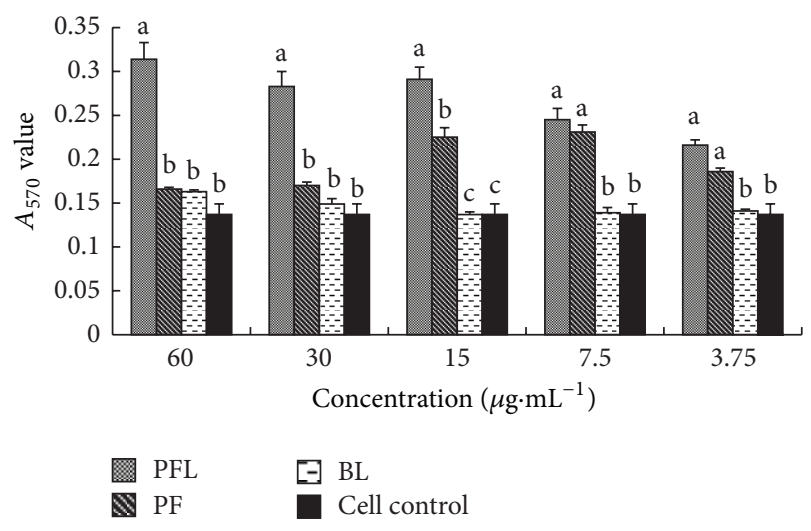

FIGURE 1: Changes of T lymphocyte proliferation in single stimulation with drugs ( $A_{570}$ values). ${ }^{\mathrm{a}-\mathrm{c}}$ Bars in the same day without the same superscripts differ significantly $(P<0.05)$.

PF groups at $60-15 \mu \mathrm{g} \cdot \mathrm{mL}^{-1}$ were significantly higher than those of $\mathrm{BL}$ and PHA groups $(P<0.05)$, and these of PFL group being significantly higher than those of PF groups $(P<0.05)$. IL-2 mRNA level of PFL group at $60 \mu \mathrm{g} \cdot \mathrm{mL}^{-1}$ was significantly higher than those of PFL at $30 \mu \mathrm{g} \cdot \mathrm{mL}^{-1}$ and $15 \mu \mathrm{g} \cdot \mathrm{mL}^{-1}$ groups, and at $30 \mu \mathrm{g} \cdot \mathrm{mL}^{-1}$ being significantly higher than at $15 \mu \mathrm{g} \cdot \mathrm{mL}^{-1}$ group.

3.3.4. Effect of PFL on Expression Level of IFN- $\gamma$ mRNA. The results are showed in Figure 4. IFN- $\gamma$ mRNA level of PFL and $\mathrm{PF}$ groups at $60-15 \mu \mathrm{g} \cdot \mathrm{mL}^{-1}$ were significantly higher than those of BL and PHA groups $(P<0.05)$ and these of PFL group being significantly higher than those of PF groups $(P<0.05)$. IFN $-\gamma$ mRNA level of PFL group at $60 \mu \mathrm{g} \cdot \mathrm{mL}^{-1}$ was significantly higher than those of PFL at $30 \mu \mathrm{g} \cdot \mathrm{mL}^{-1}$ and $15 \mu \mathrm{g} \cdot \mathrm{mL}^{-1}$ groups, and at $30 \mu \mathrm{g} \cdot \mathrm{mL}^{-1}$ being significantly higher than at $15 \mu \mathrm{g} \cdot \mathrm{mL}^{-1}$ group.

\section{Discussion}

Encapsulation efficiency is critical factor to appraise the quantity of liposome drugs and is affected with many factors. In order to achieve high encapsulation efficiency of PFL, in the experiment the preparation conditions of PFL must be optimized.

Traditionally, optimization in analytical chemistry has been carried out by monitoring the influence of one factor at a time on an experimental response. Its major disadvantage is that it does not include the interactive effects among the variables studied. As a consequence, this technique does not 


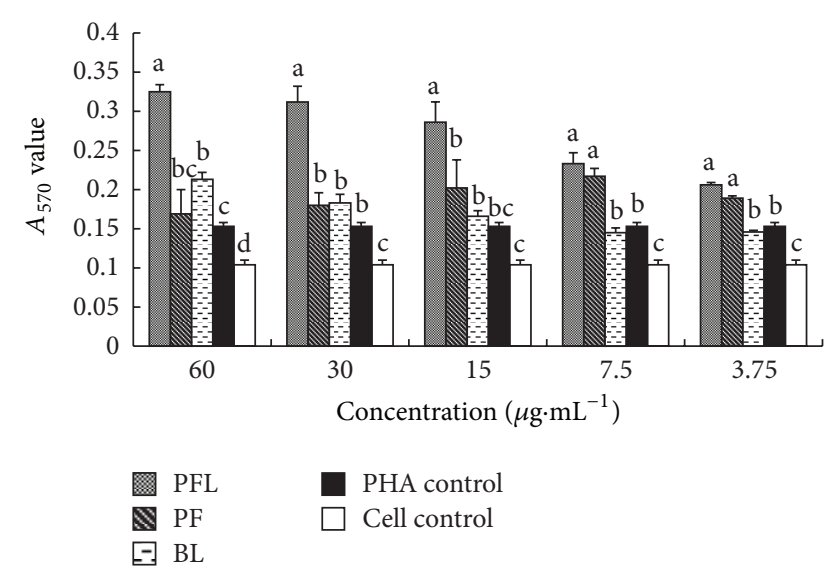

FIGURE 2: Changes of T lymphocyte proliferation in synergistical stimulation of drugs with PHA ( $A_{570}$ values). ${ }^{\mathrm{a}-\mathrm{d}}$ Bars in the same day without the same superscripts differ significantly $(P<0.05)$.

depict the complete effects of the parameter on the response $[28,29]$. Another disadvantage of the one-factor optimization is the increase in the number of experiments necessary to conduct the research, which leads to an increase of time and expenses as well as an increase in the consumption of reagents and materials. Response surface methodology is a designed regression analysis meant to predict the value of a dependent variable based on the controlled values of the independent variables [30,31]. The use of RSM in the process optimization stage leads to the need for an experimental design, which can generate a lot of samples for consumer evaluation in a short period of time, and thus laboratory level tests are more efficient [30]. The product optimization time is greatly reduced from traditional "cook and look" optimization techniques [29]. From the parameter estimates, it can be determined which variable contributes the most to the prediction model, thereby allowing the product researcher to focus on the variables that are most important to the product acceptance [32].

Therefore, in the study, preparation conditions of PFL must be optimized with response surface methodology (RSM). The optimization of PFL was ratio of lipid to drug (w/w) of $9.6: 1$, ratio of soybean phospholipid to cholesterol $(\mathrm{w} / \mathrm{w})$ of $8.5: 1$, speed of injection $0.8 \mathrm{~mL} \cdot \mathrm{min}^{-1}$, and mean encapsulation efficiency of $91.67 \pm 0.21 \%$. It was similar to the predicted value $91.59 \%$, which indicated that the model was adequate for the preparation process.

In vitro, the immunomodulatory activity was compared between PFL and PF. The results showed that whether in single stimulation or in synergistical stimulation with PHA, the $A_{570}$ values of PFL group in certain concentrations (15$60 \mu \mathrm{g} \cdot \mathrm{mL}^{-1}$ ) were significantly higher than those of PF group (Figures 1 and 2). Furthermore, the results suggested that at concentrations of $15-60 \mu \mathrm{g} \cdot \mathrm{mL}^{-1}$, the expressions of IL-2 mRNA and IFN- $\gamma$ mRNA in PFL group were significantly higher than those in PF group (Figure 3 and Figure 4); in addition, the increases of expressions of IL-2 mRNA and IFN $-\gamma$ mRNA in PFL group were significant from $15 \mu \mathrm{g} \cdot \mathrm{mL}^{-1}$

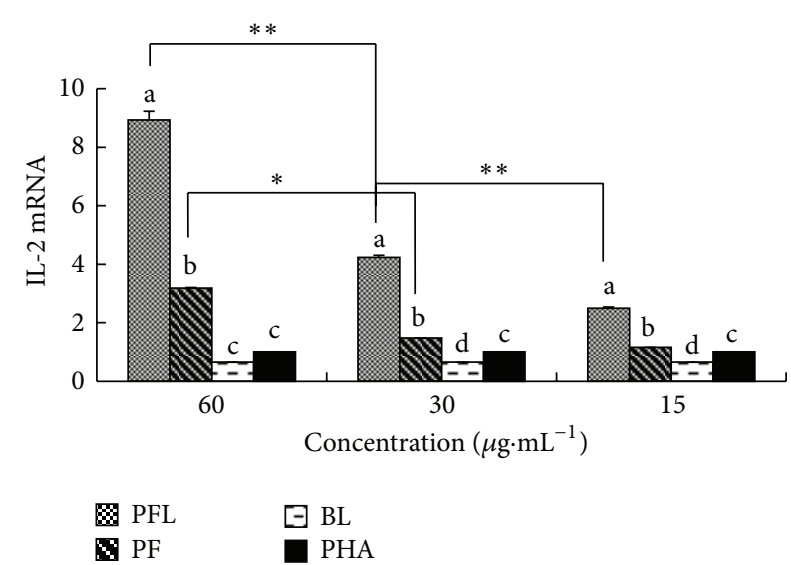

FIGURE 3: Effect of PFL on expression level of IL-2 mRNA. ${ }^{\mathrm{a}-\mathrm{d}}$ Bars in the same day without the same superscripts differ significantly $(P<$ $0.05)$. ${ }^{*}$ means significantly different between two groups $(P<0.05)$. ${ }^{* *}$ means significantly different between two groups $(P<0.01)$.

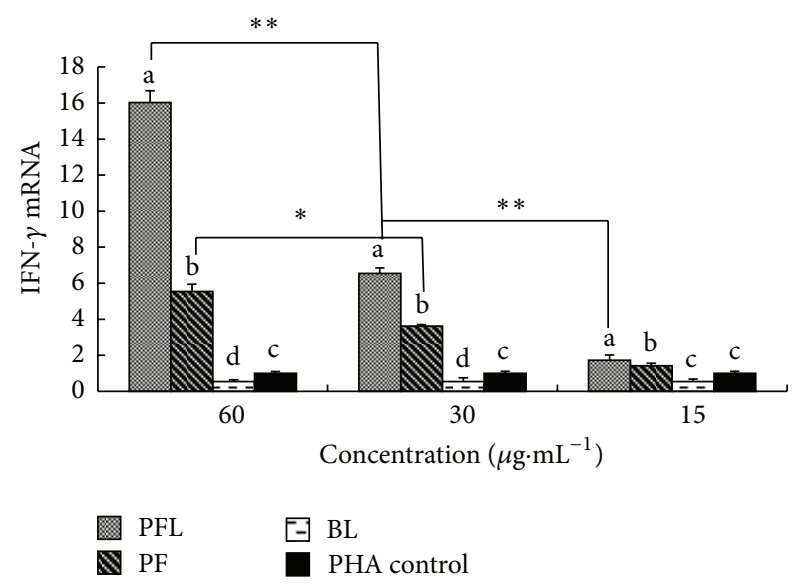

FIGURE 4: Effect of PFL on expression level of IFN- $\gamma$ mRNA. ${ }^{a-d}$ Bars in the same day without the same superscripts differ significantly $(P<0.05)$. * means significantly different between two groups $(P<0.05) .{ }^{* *}$ means significantly different between two groups $(P<0.01)$.

to $60 \mu \mathrm{g} \cdot \mathrm{mL}^{-1}$. These indicated that the immunomodulatory activity of PFL was related with concentrations, when the higher the concentration was, the better the immunomodulatory activity was. Which indicated that the immunomodulatory activity of PF was obviously promoted after PF was encapsulated with liposome, and higher encapsulation efficiency played important role in the immunomodulatory activity of PFL.

In conclusion, PFL was prepared by ethanol injection method, and the preparation conditions of PFL were optimized with RSM. The optimal preparation conditions for PFL was as follows: ratio of lipid to drug (w/w) $9.6: 1$, ratio of soybean phospholipid to cholesterol $(\mathrm{w} / \mathrm{w}) 8.5: 1$, and speed of injection $0.8 \mathrm{~mL} \cdot \mathrm{min}^{-1}$. Under these conditions, the experimental encapsulation efficiency of PFL was $91.67 \pm$ $0.21 \%$. In vitro, PFL not only could significantly promote $\mathrm{T}$ 
lymphocytes proliferation singly or synergistically with PHA, but also could increase the expression levels of IL-2 and IFN$\gamma$ mRNA, demonstrated the stronger immunoenhancement activity, which provides the theoretical basis for the further experiment in vivo.

$\begin{array}{ll}\text { Abbreviations } \\ \text { PF: } & \text { Propolis flavonoids } \\ \text { PFL: } & \text { Propolis flavonoids liposome } \\ \text { RSM: } & \text { Response surface methodology } \\ \text { PHA: } & \text { Phytohemagglutinin } \\ \text { ELISA: } & \text { Enzyme-linked immunosorbent assay } \\ \text { MTT: } & \text { 3-(4,5-dimethylthiazol-2-yl)-2,5- } \\ & \text { diphenyltetrazolium bromide } \\ \text { CMF: } & \text { Calcium and magnesium-free } \\ \text { PBS: } & \text { Phosphate-buffered saline } \\ \text { DMSO: } & \text { Dimethyl sulfoxide } \\ \text { EE: } & \text { Entrapment efficiency } \\ \text { BBD: } & \text { Box-Behnken design } \\ \text { BL: } & \text { Blank liposomes } \\ \text { BC: } & \text { Blank control } \\ \text { IL-2: } & \text { Interleukin- } 2 \\ \text { IFN- } \gamma: & \text { Interferon- } \gamma \text {. }\end{array}$

\section{Authors' Contribution}

J. Yuan and Y. Lu contributed equally to this work.

\section{Acknowledgments}

The project was supported by National Natural Science Foundation of China (Grant no. 30901085), the Fundamental Research Funds for the Central Universities (Grant no. KYZ201117), Special Fund for Agro-scientific Research in the Public Interest (Grant no. 201303046), and a Project Funded by the Priority Academic Program Development of Jiangsu Higher Education Institutions (PAPD). The authors are grateful to all other staff in the Institute of Traditional Chinese Veterinary Medicine of Nanjing Agricultural University for their assistances in the experiments.

\section{References}

[1] J. M. Sforcin and V. Bankova, "Propolis: is there a potential for the development of new drugs? of Ethnopharmacology," Journal of Ethnopharmacology, vol. 133, no. 2, pp. 253-260, 2011.

[2] A. H. Banskota, Y. Tezuka, and S. Kadota, "Recent progress in pharmacological research of propolis," Phytotherapy Research, vol. 15, no. 7, pp. 561-571, 2001.

[3] J. M. Sforcin, "Propolis and the immune system: a review," Journal of Ethnopharmacology, vol. 113, no. 1, pp. 1-14, 2007.

[4] Y. Shinmei, H. Yano, Y. Kagawa et al., "Effect of Brazilian propolis on sneezing and nasal rubbing in experimental allergic rhinitis of mice," Immunopharmacology and Immunotoxicology, vol. 31, no. 4, pp. 688-693, 2009.

[5] M. C. Búfalo, J. M. Candeias, and J. M. Sforcin, "In vitro cytotoxic effect of Brazilian green propolis on human laryngeal epidermoid carcinoma (HEp-2) cells," Evidence-Based Complementary and Alternative Medicine, vol. 6, no. 4, pp. 483-487, 2009.

[6] S. A. de Moura, M. A. Ferreira, S. P. Andrade, M. L. Reis, M. L. Noviello, and D. C. Cara, "Brazilian green propolis inhibits inflammatory angiogenesis in a murine sponge model," Evidence-Based Complementary and Alternative Medicine, vol. 2011, Article ID 182703, 7 pages, 2011.

[7] É. W. Teixeira, D. Message, G. Negri, A. Salatino, and P. C. Stringheta, "Seasonal variation, chemical composition and antioxidant activity of brazilian propolis samples," EvidenceBased Complementary and Alternative Medicine, vol. 7, no. 3, pp. 307-315, 2010.

[8] T. Shimizu, Y. Takeshita, Y. Takamori et al., "Efficacy of Brazilian propolis against herpes simplex virus type 1 infection in mice and their modes of antiherpetic efficacies," Evidence-Based Complementary and Alternative Medicine, vol. 2011, Article ID 976196, 9 pages, 2011.

[9] K. F. Dota, M. E. Consolaro, T. I. Svidzinski, and M. L. Bruschi, "Antifungal activity of Brazilian propolis microparticles against yeasts isolated from vulvovaginal candidiasis," Evidence-Based Complementary and Alternative Medicine, vol. 2011, Article ID 201953, 8 pages, 2011.

[10] K. Salomão, E. M. de Souza, A. Henriques-Pons, H. S. Barbosa, and S. L. de Castro, "Brazilian green propolis: effects in vitro and in vivo on trypanosoma cruzi," Evidence-Based Complementary and Alternative Medicine, vol. 2011, Article ID 185918, 11 pages, 2011.

[11] B. C. B. S. Mello, J. C. C. Petrus, and M. D. Hubinger, "Concentration of flavonoids and phenolic compounds in aqueous and ethanolic propolis extracts through nanofiltration," Journal of Food Engineering, vol. 96, no. 4, pp. 533-539, 2010.

[12] S. Mohammadzadeh, M. Sharriatpanahi, M. Hamedi, Y. Amanzadeh, S. E. Sadat Ebrahimi, and S. N. Ostad, "Antioxidant power of Iranian propolis extract," Food Chemistry, vol. 103, no. 3, pp. 729-733, 2007.

[13] B. Trusheva, M. Popova, E. B. Koendhori, I. Tsvetkova, C. Naydenski, and V. Bankova, "Indonesian propolis: chemical composition, biological activity and botanical origin," Natural Product Research, vol. 25, no. 6, pp. 606-613, 2011.

[14] T. Irie, S. Watarai, and H. Kodama, "Humoral immune response of carp (Cyprinus carpio) induced by oral immunization with liposome-entrapped antigen," Developmental and Comparative Immunology, vol. 27, no. 5, pp. 413-421, 2003.

[15] N. R. Draper and J. A. John, "Response-surface designs for quantitative and qualitative variables," Technometrics, vol. 30, pp. 423-428, 1998.

[16] R. H. Myers and D. C. Montgomery, Response Surface Methodology, John Wiley \& Sons, New York, NY, USA, 2002.

[17] N. Aktaş, "Optimization of biopolymerization rate by response surface methodology (RSM)," Enzyme and Microbial Technology, vol. 37, no. 4, pp. 441-447, 2005.

[18] Y. Lu, J. Li, and G. Wang, "In vitro and in vivo evaluation of mPEG-PLA modified liposomes loaded glycyrrhetinic acid," International Journal of Pharmaceutics, vol. 356, no. 1-2, pp. 274281, 2008.

[19] L. Wang and X. M. Ge, "Curcumin liposomes and quality evaluation studies," Food Science Technology, vol. 35, pp. 203206, 2010.

[20] Y. Zhang, S. X. Zeng, and B. D. Zheng, "Study on the processing condition of extracting total flavonoids from shaddock peel," 
Chinese Agricultural Science Bulletin, vol. 27, no. 14, pp. 100-103, 2011.

[21] K. K. Gunter, T. E. Gunter, A. Jarkowski, and R. N. Rosier, “A method of resuspending small vesicles separated from suspension by protamine aggregation and centrifugation," Analytical Biochemistry, vol. 120, no. 1, pp. 113-124, 1982.

[22] X. J. Zhao, J. G. Liu, Y. L. Hu et al., "Optimization on condition of glycyrrhetinic acid liposome by RSM and the research of its immunological activity," International Journal of Biological Macromolecules, vol. 51, pp. 299-304, 2012.

[23] Y. Fan, Y. Hu, D. Wang et al., "Effects of Astragalus polysaccharide liposome on lymphocyte proliferation in vitro and adjuvanticity in vivo," Carbohydrate Polymers, vol. 88, no. 1, pp. 68-74, 2012.

[24] X. Zhao, Y. Fan, D. Wang et al., "Immunological adjuvant efficacy of glycyrrhetinic acid liposome against Newcastle disease vaccine," Vaccine, vol. 29, no. 52, pp. 9611-9617, 2011.

[25] P. T. Huang, Ed., Experimental Direction of Molecule Clone, Science Press, Marrickville, Australia, 2002.

[26] K. M. Ririen, R. P. Rasmussen, and C. T. Wittwer, "Product differentiation by analysis of DNA melting curves during the polymerase chain reaction," Analytical Biochemistry, vol. 245, pp. 154-160, 1997.

[27] K. J. Livak and T. D. Schmittgen, "Analysis of relative gene expression data using real-time quantitative PCR and the $2^{-\Delta \Delta C T}$ method," Methods, vol. 25, no. 4, pp. 402-408, 2001.

[28] T. Lundstedt, E. Seifert, L. Abramo et al., "Experimental design and optimization," Chemometrics and Intelligent Laboratory Systems, vol. 42, pp. 3-40, 1998.

[29] N. Aktaş, "Optimization of biopolymerization rate by response surface methodology (RSM)," Enzyme and Microbial Technology, vol. 37, no. 4, pp. 441-447, 2005.

[30] W. C. Lee, S. Yusof, N. S. A. Hamid, and B. S. Baharin, "Optimizing conditions for hot water extraction of banana juice using response surface methodology (RSM)," Journal of Food Engineering, vol. 75, no. 4, pp. 473-479, 2006.

[31] A. B. Marcos, E. S. Ricardo, P. O. Eliane, S. V. Leonardo, and A. E. Luciane, "Response surface methodology (RSM) as a tool for optimization in analytical chemistry," Talanta, vol. 76, pp. 965977, 2008.

[32] H. G. Schutz, "Multiple regression approach to optimization," Food Technology, vol. 37, no. 62, pp. 46-48, 1983. 


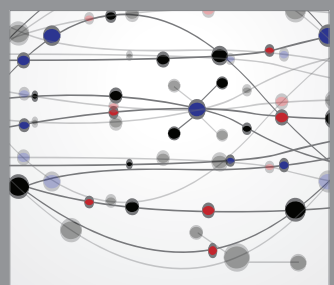

The Scientific World Journal
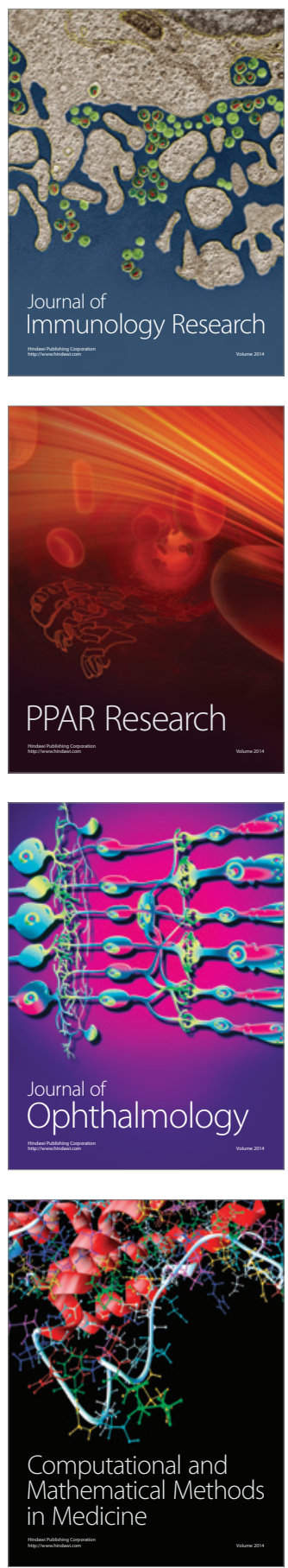

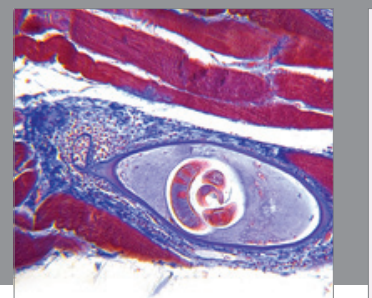

Gastroenterology

Research and Practice
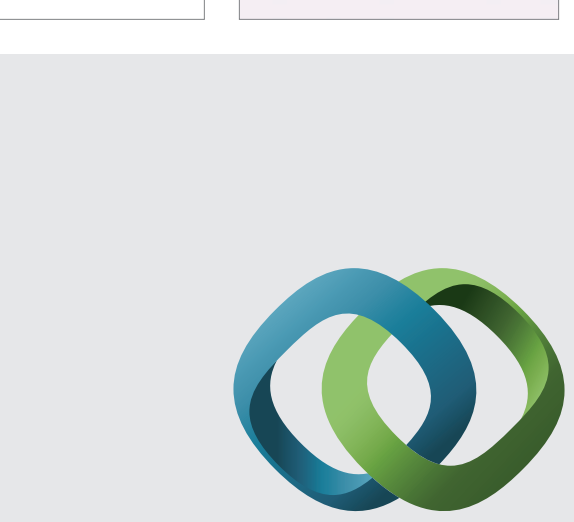

\section{Hindawi}

Submit your manuscripts at

http://www.hindawi.com
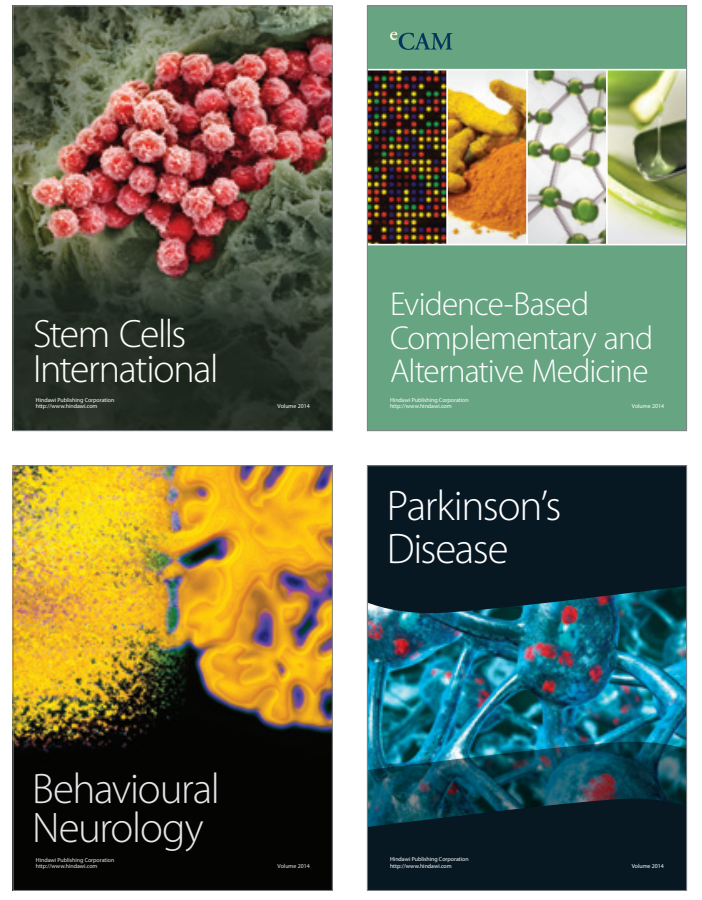
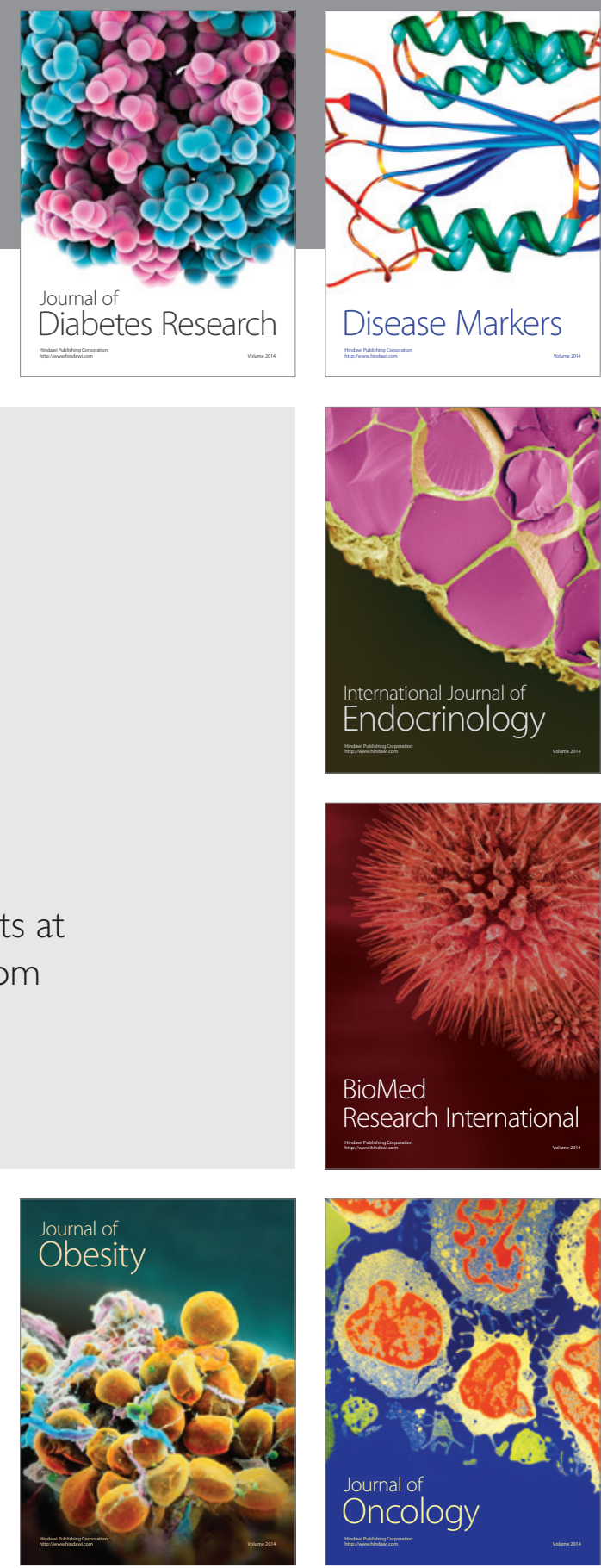

Disease Markers
